\title{
A filosofia como disciplina curricular no contexto da educaçáo brasileira: aspectos metodológicos e históricos ancorados nas teorias de currículo
}

\author{
Letícia Maria Passos Corrêa* \\ Neiva Afonso Oliveira**
}

\begin{abstract}
Resumo
O artigo apresenta discussóes sobre o papel da disciplina Filosofia no contexto educacional brasileiro. São abordados, no texto, dois pontos centrais: a discussão relativa a como ensinar Filosofia e um breve relato da história recente da disciplina Filosofia na Educação Brasileira. O trabalho foi desenvolvido através de pesquisa qualitativa e bibliográfica com base nas teorias de currículo abordadas na obra de Alice Casimiro Lopes e Elizabeth Macedo e de estudiosos sobre o Ensino de Filosofia, como Mário Sérgio Cortella, Jorge Dutra e Ronai Rocha. O estudo aponta para a necessidade de se pensar o status da disciplina Filosofia, no atual momento, no ensino médio, e visa defender a necessidade de compreender os processos que a disciplina enfrenta a fim de refletir acerca do papel da Filosofia para os jovens de hoje na educação básica Palavras-chave: ensino de filosofia, teorias de currículo, educação brasileira.
\end{abstract}

\section{Philosophy as curricular discipline in brazilian education context: historical and methodological aspects anchored in some Curriculum Theories}

\begin{abstract}
The text presents discussions about the role Philosophy as a Disciplin has in Brazilian context. Two main topics are treated: the discussion related to how teach Philosophy and a brief description of recent moments of philosophy in Brazilian context. The investigation was developed by bibliographical and qualitative research starting from Curriculum Theories which approach is given by Alice Casimiro Lopes and Elizabeth Macedo's texts and Philosophy teaching scholars, such as Mário Sérgio Cortella, Jorge Dutra and Ronai Rocha. The study indicates the urgency of problematizing the status that philosophy hasin High School, nowadays. Also, we intend to defend the necessity of understanding the processes faced by the discipline with the purpose of

* Licenciada em Filosofia, Mestra e Doutora em Educação, com ênfase em Filosofia e História da Educação, pela Universidade Federal de Pelotas, e Professora de Filosofia na Universidade Federal do Rio Grande (FURG) e na SEDUC/RS. E-mail: leticiampcorrea@gmail.com.

** Licenciada em Filosofia pela Universidade Católica de Pelotas, Mestre e Doutora em Filosofia pela Pontifícia Universidade Católica do Rio Grande do Sul. Pós-Doutora em Filosofia pela UFSC e Professora/Orientadora no PPGE/UFPel. E-mail: neivaafonsooliveira@gmail.com.
\end{abstract}


thinking about philosophy and youth in our days.

Keywords: philosophy teaching, curriculum theories, Brazilian education.

No horizonte da educação brasileira contemporânea, percebe-se que, por mais que tenhamos em mente que o ideal seria um conhecimento totalizante, que integre os conteúdos e inter-relacione os saberes - em vez de termos um ensino com várias "gavetas", cada qual abrigando um conhecimento que, por vezes, náo se conecta com os demais - a organizaçáo por meio de disciplinas escolares é algo que se faz necessário, em função da logística de funcionamento das escolas e, em face das peculiaridades que cada disciplina apresenta, exigindo, assim, metodologias diversas por parte dos docentes que as lecionam. E, por mais que uma disciplina escolar seja direcionada a um significativo número de alunos, para cada um dos estudantes, ela constitui uma experiência singular, em que serão vivenciadas diversas maneiras particulares de, individualmente, o aluno formar-se pelos conteúdos trabalhados em sala de aula.

Como professoras de Filosofia, preocupamo-nos com vários pontos que a cercam. Dessa forma, acreditamos ser relevante descrever alguns aspectos da disciplina Filosofia na história recente e no contexto atual da educação brasileira. No presente texto são expostos fundamentos teóricos oriundos das teorias de currículo, tomando como referencial teórico central a obra Teorias de currículo, de Alice Casimiro Lopes e Elizabeth Macedo, que conta com um capítulo especialmente direcionado à temática das disciplinas escolares. Enfatizaremos a discussão a respeito das disciplinas, expondo alguns autores curriculistas, trabalhados pelas autoras Lopes e Macedo, relacionando-os com a disciplina Filosofia. Assim, serão apresentados alguns elementos metodológicos e históricos referentes à disciplina em questão.

\section{Como ensinar Filosofia?}

Pensar sobre uma metodologia de ensino enseja o aparecimento de várias incógnitas. As principais preocupaçôes metodológicas dos educadores dizem respeito à escolha dos conteúdos, à seleção de materiais e utensílios metodológicos, aos objetivos que a disciplina se propóe a atingir e à postura que o educador assume no processo de ensino. John Dewey (2011, p. 69) menciona o processo metodológico do Ensino de Filosofia: 
A Filosofia começa com uma maneira, de certa forma, profunda e ampla de responder às dificuldades que a vida apresenta, mas se desenvolve apenas quando encontra os materiais necessários para que essa resposta seja consciente, articulada e comunicável.

$\mathrm{Na}$ proposta de pensarmos a Filosofia por meio de seu enfoque metodológico, com base em pesquisas relacionadas ao Ensino de Filosofia, defendemos a afirmação de que, no momento atual, três principais concepçóes sobre como ensinar Filosofia, extraídas de excertos de três filósofos (Kant, Hegel e Lipman), figuram como principais modelos norteadores para a prática do ensino de Filosofia. As discussóes sobre o ensino de Filosofia contornam as metodologias apontadas por Kant, que era enfático ao afirmar que "não se ensina filosofia, se ensina a filosofar" (KANT, 1992, p. 174), valorizando a formação do aluno/filósofo; Hegel, que, por sua vez, afirmava que ao "aprender a conhecer o conteúdo da filosofia não se aprende apenas o filosofar, mas também já se filosofa efetivamente” (HEGEL, 1978, p. 141), ou seja, que se ensina filosofia pela história da filosofia; e Lipman, com seu programa de Ensino de Filosofia para Crianças, cuja assertiva "temos que aprender a ensinar as crianças a pensar por si mesmas se desejamos ter uma democracia que vale a pena ter" (LIPMAN, 1995, p. 159), coincide com nossa afirmação de que não são estas as únicas possibilidades presentes no ensino de Filosofia. Dutra (2010, p. 49-50) apresenta outras seis abordagens do ensino dessa disciplina. São elas:

1)O ensino por "temas filosóficos", amparado nos escritos de Marilena Chauí e outros autores que redigiram livros didáticos de grande distribuição no território brasileiro.

2)O ensino através de "campos filosóficos", amparados nas escolas filosóficas presentes na história da Filosofia.

3) O modelo de ensino a partir de "problemas filosóficos", por exemplo, a metafísica, o ser etc.

4) O ensino com base em "critérios cronológicos", amparando-se na ordem temporal dos acontecimentos que marcaram a história da Filosofia, "encaixando-se", assim, no modelo hegeliano de ensinar Filosofia.

5)O ensino direcionado ao desenvolvimento de "atitudes filosóficas". Ou seja, à proposta de "despertar", no educando, habilidades de pensamento cognitivas, críticas e formativas; congruente com o modelo kantiano de "ensinar a filosofar". 
6)O ensino da Filosofia como uma atividade de "criação de conceitos"; em consonância com os pensamentos de Deleuze e Guattari, que definem a Filosofia como "a disciplina que consiste em criar conceitos" (DELEUZE; GUATTARI, 1992, p. 13, grifo do autor).

Retomando a afirmativa feita anteriormente, em que apontamos Kant, Hegel e Lipman como alguns dos principais referenciais teóricos utilizados atualmente nos modelos curriculares de ensino de Filosofia, cabe frisar que há, entre eles, uma linha muito tênue nas divisóes de tais enfoques metodológicos. Exemplificando, Georg Wilhelm Friedrich Hegel não se distanciara totalmente do enfoque kantiano, pois, ao mesmo tempo em que se aprende a Filosofia por seus dados históricos também são exercitados o pensamento e o filosofar. Assim, as três abordagens, somadas aos modelos apresentados por Jorge da Cunha Dutra (2010, p. 49-50) passam-nos a ideia de que, ao ensinar Filosofia, estaríamos realizando um exercício que envolve: a) uma atividade prática; b) o conhecimento das tradiçóes e estudos filosóficos; e c) a proposta de desenvolvimento de habilidades formativas de pensamento.

Lipman, ao focar seu projeto em um filosofar que tenha suas "raízes" na infância, apresenta-nos a possibilidade de relacionar a abordagem kantiana com a abordagem de Jerome Bruner, ${ }^{1}$ que assinala que todas as disciplinas devem ter uma proposta curricular que seja acessível a variadas pessoas, cuja lógica se possa aprender e cujos fundamentos epistemológicos norteadores possamos capturar. Lopes e Macedo (2011, p. 114) comentam que, para Bruner, "não basta o aluno captar os princípios gerais. É preciso formar no aluno uma atitude em relação à aprendizagem e à investigação, de maneira que ele seja capaz de resolver problemas reais". Ou seja, assim pensando, não se ensina uma disciplina, ensina-se uma capacidade cognitiva, uma habilidade de pensamento contida em determinada disciplina, que possa servir para a própria vivência geral. Tal capacidade cognitiva implica no reconhecimento de um saber prático, que diz respeito à vida real e cotidiana com que os indivíduos se confrontam diariamente. Para tanto, a Filosofia necessita desse olhar que a "retire" do "mundo ideal" e a traga para

1 Jerome Seymour Bruner é um psicólogo norte-americano, nascido em 1915. Fez seu doutoramento na Universidade de Harvard, onde, posteriormente, lecionou por muitos anos. Possui uma obra que realiza uma intersecção entre Psicologia e Pedagogia. Seus escritos repercutiram muito no âmbito da Educação em função da contribuição destinada às teorias de currículo. Atualmente, é professor na New York University. 
a realidade vivenciada por nós e nossos alunos. Dewey defende essa ideia, na obra Reconstrução em Filosofia:

$\mathrm{O}$ ideal e o racional representam possibilidades inteligentemente engendradas do mundo existente, que podem ser empregadas como métodos para o modificar e aperfeiçoar. Filosoficamente falando, esta é a grande diferença contida na mudança da natureza do conhecimento e da filosofia, de contemplativa para operativa. Tal mudança não envolve diminuição da dignidade da filosofia, nem a remoçáo desta de um plano elevado para um grosseiro utilitarismo. Significa, sim, que a função primordial da filosofia é a de explorar racionalmente as possibilidades da experiência; especialmente as da experiência humana coletiva. $\mathrm{O}$ alcance desta mudança pode ser compreendido pela simples consideração de quão longe estamos de consegui-la. (2011, p. 113).

Outro ponto que merece atenção com relação à disciplina Filosofia diz respeito ao que Ivor Goodson, curriculista, com trabalhos de destaque nas décadas de 1980 e 1990, menciona quando se refere à vinculação das disciplinas escolares com os processos de exclusão social.

Para o autor, quanto mais uma disciplina for próxima do padrão universitário, entendido como um padrão academicista, descolado da realidade do educando, maior será o afastamento dos alunos no que concerne ao interesse pelos conteúdos ensinados. Infelizmente, no caso da Filosofia, podemos dizer que é um fato a ser considerado. Alguns docentes optam por conservar um linguajar pedante, com textos rebuscados e ideias complexas. Em alguns casos, em função de tamanha elitização, que serve apenas para enaltecer o ego do docente que a promove ao falar de coisas que ninguém, com exceção dele mesmo, entende; os alunos, por outro lado, se perguntam: "Afinal, para que devo estudar Filosofia?".

Em momento algum, apontarei a banalização da Filosofia por meio de uma simplificação de seus conteúdos. Entretanto, não podemos nos esquecer do papel que a disciplina desempenha e a quem ela se refere. Uma disciplina deve "falar a língua" de seu público. No processo de transposição didática, se os conteúdos forem, na medida certa, contextualizados e fizerem sentido para o corpo discente, passarão a se comportar não apenas como informaçóes que "servem para passar nas provas", mas também podem representar algo que contribua com suas vidas, com seus pensares, com sua cognição. 


\section{A trajetória da Filosofia como disciplina curricular}

Avançando para um enfoque histórico, ancorado em Goodson, propomo-nos a desvendar alguns dos aspectos sócio-históricos da disciplina em questấo. $^{2}$

As indagaçóes começam com as seguintes perguntas: por que uma disciplina é escolhida para integrar o currículo de um curso, em detrimento de tantas outras que poderiam ser escolhidas? Ou, dito de outra forma, por que, em momentos distintos, uma disciplina é excluída das organizaçôes curriculares? ${ }^{3}$ Tais questóes dizem respeito à estabilidade, bem como às mudanças que acontecem com o passar do tempo nos conteúdos e nas disciplinas que são escolhidas para suprir a formação humana dos alunos que frequentarão os ambientes escolares.

Quando nos referimos ao conceito de formação humana, partimos de elementos de três modelos filosóficos: Paideia, Humanitas e Bildung. Entretanto, a Bildung, por carregar consigo ideais de liberdade, autonomia e emancipação é o modelo de formação humana que mais se "encaixa" nos ideais que temos em mente quando afirmamos que o ensino de Filosofia contribui para a formação humana, para o autocultivo e para a compreensão da existência humana.

Sendo assim, a escolha de uma disciplina em um ambiente escolar não é obra do acaso, muito menos uma questão de gosto aleatório daqueles que a elegem. As disciplinas escolares, selecionadas por autoridades e estudiosos que a inserem no cotidiano dos alunos, simbolizam o espectro de uma sociedade. Dizem muito sobre o que esta sociedade considera importante e o que valoriza para compor a educação dos jovens. Paradoxalmente, a formação humana é composta, em grande parte, pela formação escolar. Espera-se, portanto, um cuidado maior dos gestores para a formação escolar, mas, infelizmente, o que se vê é que a condução do país se dá por meio de pessoas que raramente são afeitas à valorização da educação básica, tratando

2 A temática a respeito da trajetória histórica da Filosofia na realidade brasileira foi abordada por nós, na dissertação de mestrado de Letícia Maria Passos Corrêa e orientada por Neiva Afonso Oliveira. Sendo assim, este tema consiste em um dos aspectos genealógicos que deram origem às nossas atuais pesquisas. Para maiores esclarecimentos a respeito do caráter sócio-histórico da Filosofia como disciplina curricular da educação básica, ver Ensino de Filosofia: um estudo de caso (Corrêa, 2012).

3 Embora tais questionamentos náo componham o cerne da temática deste artigo, pensamos que são perguntas fundamentais a serem feitas quando nos perguntamos sobre os porquês a respeito da trajetória peculiar a que a Filosofia tem percorrido na educação brasileira. 
com descaso uma área que merece total atenção. Assim, ao eleger uma ou outra disciplina, estão em jogo relaçôes de poder, princípios utilitários e ideais de cultura e de educação.

Por muitos anos, a ação de planejar o currículo confundiu-se com a própria noção de currículo. Numa tentativa de entendimento da evolução das disciplinas escolares, Goodson aplica um modelo desenvolvido por David Layton, aplicado ao estudo das ciências naturais. Com base no estudo de Layton, Goodson chega a três conclusôes fundamentais para entendermos os estágios trilhados por uma disciplina escolar:

A primeira conclusão é que as matérias não constituem entidades monolíticas, mas amálgamas mutáveis de subgrupos e tradiçóes que, mediante controvérsias e compromisso, influenciam a direção de mudança. Em segundo lugar, o processo de se tornar uma matéria escolar caracteriza a evolução da comunidade, que passa de uma comunidade que promove objetivos pedagógicos e utilitários para uma comunidade que define a matéria como uma "disciplina" acadêmica ligada com estudiosos de universidades. Em terceiro lugar, o debate em torno do currículo pode ser interpretado em termos de conflito entre matérias em relação a status, recursos e território. (GOODSON, 1995, p. 120).

Layton afirma que existem três estágios evolutivos pelos quais passam uma disciplina escolar. Primeiramente, uma disciplina é introduzida em um contexto escolar com base na necessidade pragmática de utilidade social. Posteriormente, a disciplina passa a desempenhar um papel tradicional e os professores que a lecionam começam a ter formação específica para o trabalho docente. Por fim, acontece a etapa de consolidação no currículo, por meio de um corpo docente formado e do status social que a disciplina passa a exercer.

Entretanto, a trajetória linear descrita por Layton não é seguida por todas as disciplinas. A Filosofia, na realidade brasileira, é um grande exemplo de uma disciplina que não segue a tais regras, pois:

É muito interessante observar o quanto a Filosofia padece de certa ambiguidade quando se procura o sentido de sua inserção em uma grade curricular de Ensino Médio: quase nenhum educador deixaria de incluí-la como necessária, assim como quase nenhuma ditadura deixaria de excluí-la como perigosa! (CORTELLA, 2009, p. 17, grifo do autor). 
No início da década de 1960, o contexto desenhado, no campo da educação brasileira, trazia uma reforma. Era criada a Lei de Diretrizes e Bases (LDB). Pela Lei $n^{\circ}$ 4.024, de 20 de dezembro de 1961, havia a possibilidade de os Conselhos Estaduais de Educação indicarem disciplinas complementares e optativas aos estabelecimentos de ensino, dita desta forma:

Em cada ciclo haverá disciplinas e práticas educativas, obrigatórias e optativas. $\$ 1^{\circ}$ - Ao Conselho Federal de Educação compete indicar, para todos os sistemas de ensino médio, até cinco disciplinas obrigatórias, cabendo aos conselhos estaduais de educação completar o seu número e relacionar as de caráter optativo que podem ser adotadas pelos estabelecimentos de ensino. (BRASIL, 1961).

A Filosofia passa de disciplina obrigatória ao posto de disciplina complementar, ou seja, optativa aos estabelecimentos de ensino. Esta era, então, a situação da disciplina de Filosofia no contexto que antecedia o Golpe Militar de 1964. Os fatos que se sucederam nos anos seguintes, relativos à retirada da Filosofia dos currículos escolares, não aconteceram de um instante para o outro, foram o mais claro reflexo de um processo que já vinha acontecendo nos anos anteriores e que sofreu influência de todos os acontecimentos ocorridos tanto no restante do Brasil quanto em outras partes do mundo.

Cruz Costa pode ser visto como um "visionário" desses fatos. Em sua obra, Panorama da história da filosofia no Brasil, escrita no ano de 1960, já nos fornece algumas pistas do que estava para acontecer nos próximos anos: "Discutiu-se, e continua a ser discutida, a posição da Filosofia no currículo secundário. Há quem hoje queira eliminá-la deste currículo como ontem também houve quem assim pensasse" (COSTA, 1960, p. 112).

Adiante, o autor volta a falar sobre a iminência da extinção do ensino de Filosofia no Brasil, que se daria alguns anos após: "Proponho, desde logo, [...] uma declaração, firme e decidida a favor da manutenção do ensino da Filosofia no currículo do ensino secundário, hoje ameaçado por uma nova reforma que, parece, pretende eliminá-lo" (COSTA, 1960, p. 113).

Os acontecimentos que viriam a seguir foram intuídos de alguma maneira por professores atentos aos acontecimentos sociopolíticos de seu país, como foi o caso do professor Cruz Costa.

Sobre o Decreto-Lei no 4.024, também chamado de Lei de Diretrizes e Bases de 1961, e a posterior extinção do ensino de Filosofia no contexto brasileiro, Marilena Chauí afirma: 
Cumpre lembrar, antes de tudo, que a supressão é facilitada pelo fato de ter sido precedida pela passagem da Filosofia à condição de optativa, de sorte que sua quase inexistência anterior preparou gradativamente um consenso difuso acerca de sua abolição necessária. (1978, p. 8).

Assim, a retirada do ensino de Filosofia das escolas não foi um processo que se deu de um instante para o outro. Aconteceu através de pequenas mudanças iniciais nos currículos, até o momento do ato derradeiro, o da implantação de um sistema de ensino que não mais privilegiava o pensar e a reflexão filosófica.

De 1964 a 1972, por meio do Decreto-Lei n 869/69, as disciplinas Educação Moral e Cívica e Organização Social e Política Brasileira foram incluídas na grade curricular das escolas. Concluímos que a Filosofia náo foi extinta das escolas de maneira ocasional, em razão da conjuntura dos fatos da época. Pensamos que sua extinção ocorreu gradativamente, em uma primeira instância através da retirada de seu caráter obrigatório em 1961 e, num segundo momento, através da inserção das disciplinas Educação Moral e Cívica (EMC) e Organização Social e Política Brasileira (OSPB), com a finalidade de substituição dos conteúdos filosóficos pelos pensamentos cívicos, dogmáticos e acríticos que estariam de acordo com as proposiçóes da ditadura militar, lembrando a ideologização dos currículos instaurada naquela época.

Em 1972, momento em que se consolidou a segunda Lei de Diretrizes e Bases brasileira, a Filosofia, ao mesmo tempo em que foi praticamente esquecida pelas instituiçóes de ensino, pelo fato de não integrar o rol das disciplinas obrigatórias, tampouco das optativas, também se apresentava para os governantes como uma ameaça a uma educaçáo ditatorial que precisava formar uma nação obediente e acrítica. A melhor definição para a condição ou status da disciplina nessa época é que a possibilidade de seu ensino nas escolas brasileiras foi "sufocada" pelas circunstâncias e pelas direções de um tempo ditatorial que não proporcionava condição alguma para que seu ensino fosse desenvolvido. Houve, então, uma tentativa de reinserção da Filosofia nas escolas, pelo Projeto de Lei no 356-A, de 1983, redigido pelo deputado José Fogaça. Todavia, o projeto acabou sendo arquivado, o que comprova o "sufocamento" anteriormente mencionado por nós.

De 1985 até o ano 2000, houve o processo de redemocratização no Brasil, quando aconteceu também a promulgação da Lei no 9394/96, a atual Lei de Diretrizes e Bases da educaçáo brasileira. Nesse movimento, a Filoso- 
fia, no ano de 2001, foi vetada pelo ex-Presidente da República e Sociólogo Fernando Henrique Cardoso.

Enfim, em 2008, em outra tentativa, finalmente foi obtida a aprovação do projeto e a Filosofia retornou em caráter obrigatório nas escolas por meio da Lei no 11684, a qual: "altera o art. 36 da Lei no 9.394, de 20 de dezembro de 1996, que estabelece as diretrizes e bases da educação nacional, para incluir a Filosofia e a Sociologia como disciplinas obrigatórias nos currículos do ensino médio" (BRASIL, 2008).

Atualmente, por meio da Medida Provisória no 746, de 22 de setembro de 2016, que propóe uma reforma a ser feita nos cursos de Ensino Médio no Brasil, especula-se, novamente, a exclusão da obrigatoriedade da Filosofia dos ambientes escolares. A reforma do ensino médio é proposta pelo Governo Federal brasileiro e propóe alteraçóes na Lei de Diretrizes e Bases da Educação Brasileira. Dentre outras reinvindicaçôes, visa a exclusão da obrigatoriedade dos ensinos de Filosofia, Sociologia, Artes, Educação Física e Língua Espanhola.

Nossa atual política educacional inclui, ainda, propostas como a "Escola sem partido", apresentado através do Projeto de Lei no 193/2016, de autoria do Senador Magno Malta, que propóe um modelo de Educação em que não sejam debatidos assuntos ou temas políticos ou ideológicos nas escolas de Educação Básica, dentro do território nacional (MALTA, 2016). Apelidado pelos seus opositores de "Lei da mordaça", o projeto se mostra favorável à censura e ameaça a liberdade de expressão nos ambientes pedagógicos.

Tratando-se de educação pública, são evidentes, também, o sucateamento e a transformação da Educação em mera mercadoria, dentre outras ameaças aos processos formativos da Educação brasileira. Quando nos referimos a tal sucateamento da Educaçáo brasileira, em especial, mencionamos a aprovação do Proposta de Emenda Constitucional 241/2016, que estabelece teto para os gastos públicos e congela as despesas direcionadas à Saúde e à Educação por vinte anos (BRASIL, 2016).

Assim, em tempos demasiadamente obscuros, ensinar Filosofia é, certamente, um ato de resistência e de inconformismo ao atual modelo social brasileiro. Por meio de um olhar para a trajetória da disciplina Filosofia, é possível perceber o que Goodson quis nos dizer quando afirmava que as disciplinas não estão no currículo em função de causas naturais. Cada disciplina, e a Filosofia é um bom exemplo disso, é resultado dos interesses 
culturais e pragmáticos de cada momento histórico de uma nação. Na obra Teorias de curriculo, as autoras Alice Lopes e Elizabeth Macedo mencionam o olhar de Goodson sobre as disciplinas escolares:

Uma disciplina escolar não é decorrência de uma simplificação de conhecimentos de nível superior para o nível escolar. A disciplina escolar é construída social e politicamente nas instituiçóes escolares, para atender a finalidades sociais da educação. Essa construção é desenvolvida em meio a relaçôes de poder, de maneira que os atores envolvidos, formadores da comunidade disciplinar, empregam recursos ideológicos e materiais para desenvolverem suas missôes individuais e coletivas. O debate curricular pode ser, então, entre as disciplinas. Com isso, as disciplinas escolares tornam-se amálgamas mutáveis de subgrupos e tradiçôes. (2011, p. 119).

Outro autor que analisa a história das disciplinas escolares é Thomas Popkewitz. Para ele, "o currículo configura regras e padróes de construção da razão e da individualidade por meio das disciplinas escolares. Estas podem ser então concebidas como tecnologias de regulação social" (LOPES; MACEDO, 2011, p. 120).

A regulação social ${ }^{4}$ bem própria do conteúdo das disciplinas escolares não foge à regra quando analisamos a Filosofia como disciplina. Em tempos de ditadura, por exemplo, a Filosofia "desregulava" os alunos no que se refere aos padrões que o Estado propunha na época. Em razão de seu caráter reflexivo e crítico, foi excluída da organização curricular. Hoje, em tempos (pseudo)democráticos, podemos dizer que a Filosofia poderia servir como uma "ferramenta" interessante e indispensável, caso pretendêssemos formar alunos críticos, pensantes e compromissados com o ambiente social em que vivem.

Ao fim do capítulo que trata da temática acerca da disciplina, Lopes e Macedo concordam com Goodson e Popkewitz, afirmando que:

[...] as disciplinas são construçôes sociais que atendem a determinadas finalidades da educaçáo e, por isso, reúnem sujeitos em determinados territórios, sustentam e são sustentadas por relações de poder que produzem saberes. Como constituiçôes sociais e históricas próprias do

4 Regulação social é um conceito oriundo da Sociologia que se refere a pressôes controladoras direcionadas para indivíduos ou grupos sociais com a finalidade de reparar desvios de comportamento e de conduta adotados com relação a regras morais vigentes no âmbito da sociedade. 
processo de escolarizaçáo, envolvem lutas, conflitos e acordos vinculados a essa instituição. (2011, p. 121).

As autoras defendem que, mais do que contribuir ao processo de formação de identidades, as disciplinas escolares hibridizam sentidos pedagógicos e estes vão, gradativamente, contribuindo para a ideia de que existe um discurso disciplinar dentro de uma cultura comum que deva ser ensinada a todos (LOPES, MACEDO, 2011). Fica, assim, implícita, a ideia de um currículo universal, que possa ser ensinado a cada pessoa, em qualquer parte do mundo. Tal ideia é defendida por simpatizantes da implementação da Base Nacional Comum Curricular, que, atualmente, encontra-se em processo de construção na realidade brasileira. Entretanto, Lopes e Macedo ressaltam que, em função dos mais variados contextos e demandas, não podemos almejar um saber com demasiada abrangência, pois seria ingênuo e apressado pensarmos em conhecimentos disciplinares de uma forma global.

Pensamos que a discussão a respeito do currículo é extremamente pertinente e necessária. Nós, professores, temos um grandioso papel no seio da sociedade em que vivemos, pois lidamos com seres humanos em formação, sem esquecermos, todavia, que nós ainda somos seres em constante formação. Assim, o que pretendemos dizer é que, para que possamos exercer nossa atividade plenamente, o olhar para o currículo se faz mister. Para tanto, lembramos as palavras de Rocha (2008, p. 43):

[...] a aula de Filosofia no currículo escolar vem ao encontro de algumas exigências profundas de nossos processos argumentativos e cognitivos, e só nela existe acolhida para conceitos, temas, problemas que surgem nas demais aulas da semana escolar. Podemos, por certo, deixar essas curiosidades abandonadas a si mesmas, sem acolhimento, mas com isso a escola será mais pobre, o ensino será mais frouxo. Se isso for levado em conta, a presença da Filosofia pode fazer uma diferença no currículo escolar que há tấo pouco não suspeitávamos, pois nos acostumamos a pensar seus conteúdos fora do contexto dos saberes e atividades curriculares.

É fundamental que cada docente possa perceber o papel a que a sua disciplina se presta, consiga analisar as relaçôes de poder que estão em jogo e exerça sua crítica às lutas, conflitos e acordos que permeiam o componente curricular que está sendo ensinado. Da mesma forma, o "relacionamento" da disciplina que se leciona com as demais matérias curriculares que com- 
põem o planejamento de ensino da escola é algo crucial. No caso da Filosofia, vista como "a mãe de todas as ciências", a interdisciplinaridade é um elemento que se faz necessário.

Com o passar dos tempos, a escola, como instituição social, acabou por dicotomizar os saberes. Assim, os alunos, quando a frequentam, por vezes, recebem um ensino "descolado" dos demais. Podemos fazer uma analogia comparando a escola com um grande armário. Este armário, composto por muitas "gavetas", abrigaria todos os saberes. Os professores, em muitas situaçóes, abrem-nas e fecham-se em seus próprios compartimentos e repassam esta divisão para os educandos. Entretanto, sabemos que o ideal seria que os conhecimentos abrigados em diferentes repartiçôes pudessem "dialogar entre si". E, neste ponto, a Filosofia pode desempenhar um papel aglutinador, em que as "gavetas" desapareceriam para dar margem ao conhecimento de forma integrada:

[...] a filosofia seria não propriamente o fundamento da teoria pedagógica que, por sua vez, orientaria a ação educativa, mas uma atitude geral e uma articuladora dos nexos que se operam e dos sentidos que se descobrem na educação, com o intuito de tornar os problemas aí experimentados objetos da reflexão de seus agentes e, nesse processo reflexivo, de propiciar um pensamento que lhes seja efetivamente educativo. (PAGNI, 2014, p. 75).

Sabemos que todas as ciências são oriundas do pensar filosófico. Zilles (2004, p. 77) menciona que "[...] a Filosofia é a mãe das ciências particulares: gera-as, as desenvolve e, ao entrarem em maioridade, adquirem autonomia com seus próprios métodos". A Filosofia é um pensar que reflete sobre todos os campos do pensamento, sobre todas as ciências. A gênese de cada uma das ciências incluídas na educação básica nasce das inquietaçóes e questionamentos dos filósofos. E, ao mesmo tempo em que a Filosofia faz nascer os conhecimentos científicos, também pensa a respeito deles. Exemplificando: há áreas da Filosofia intituladas Filosofia da Matemática, Filosofia da Arte, Filosofia da Linguagem etc. Portanto, a interdisciplinaridade é uma tendência que pode fazer "brotar bons frutos" no ambiente escolar e a Filosofia pode desempenhar um papel-chave nesse contexto. 


\section{Consideraçóes finais}

Com este texto, objetivamos trazer à tona discussóes a respeito do currículo e do panorama em que a disciplina Filosofia encontra-se inserida. Procuramos discutir questóes a respeito da metodologia do Ensino de Filosofia, bem como contextualizamos os processos vividos pela disciplina nas últimas décadas na realidade brasileira.

Julgamos ser de fundamental relevância as discussóes aqui apresentadas, para que possamos pensar o paradigma educacional em que nos encontramos, bem como projetar o modelo de Educação que almejamos.

No momento em que o docente conhece diferentes teorias de currículo e identifica-se com algumas delas e/ou passa a adotá-las, um novo caminho vai sendo delineado conscientemente. Uma teoria tem o poder de indicar uma rota, uma proposta, um horizonte. Ao contrário do que popularmente o senso comum por vezes proclama, teoria e prática não são dicotômicas. Elas "andam juntas, de mãos dadas". Este imbricamento da relação entre as duas nos é lembrado por Saviani (2008) quando afirma que devemos "[...] pensar a teoria a partir da prática, porque se a prática é o fundamento da teoria, seu critério de verdade e sua finalidade, isso significa que o desenvolvimento da teoria depende da prática" (p. 107). E, para caminhar rumo a algum lugar, devemos saber que meios e quais caminhos iremos percorrer na trajetória educacional da disciplina que lecionamos. Vale lembrar o diálogo entre os personagens Alice e o Gato na obra de Lewis Carroll, onde Alice pergunta:

"O senhor poderia me dizer, por favor, qual caminho que devo tomar para sair daqui?"

"Isso depende muito de para onde você quer ir", respondeu o Gato.

"Não me importo muito para onde...", retrucou Alice.

"Então náo importa o caminho que você escolha", disse o Gato. (2009, p. 59).

Seguindo o conselho do Gato, na obra de Lewis Carroll, caso queiramos ir a algum lugar, devemos saber para onde ir. Dito de outra forma: se quisermos direcionar favoravelmente nossas práticas docentes, o planejamento, a consciência de nossos pressupostos teóricos, o conhecimento da trajetória histórica da disciplina que lecionamos e a clareza nos objetivos curriculares são elementos primordiais para atingirmos os objetivos a que 
nos propusermos. Sendo assim, o engajamento em prol da defesa do ensino de Filosofia nos cursos de ensino médio representa o caminho que queremos trilhar.

\section{Referências}

BRASIL. Congresso. Câmara dos Deputados. Proposta de emenda à Constituição $n^{\circ}$ 241/2016. Brasília, DF: Congresso Nacional, 2016. Disponível em: <http:/www.camara.gov.br/proposicoesWeb/fichadetrami tacao?idProposicao=2088351 . Acesso em: 24 fev. 2018.

BRASIL. Decreto-Lei no 4.024, de dezembro de 1961. Brasília, DF: Presidência da República: Casa Civil, 1961. Disponível em: <http://www.planalto.gov. br/ccivil_03/Leis/L4024.htm>. Acesso em: 13 dez. 2016.

BRASIL. Decreto-Lei $n^{\circ}$ 869, de 12 de setembro de 1969. Brasília, DF: Presidência da República: Casa Civil, 1969. Disponível em: <http://www. planalto.gov.br/ccivil_03/Decreto-Lei/1965-1988/Del0869.htm>. Acesso em: 10 de ago. 2011.

BRASIL. Lei no 11.684, de 2 de junho de 2008. Brasília, DF: Presidência da República: Casa Civil, 2008. Disponível em: <http://www.planalto.gov.br/ ccivil_03/_Ato2007-2010/2008/Lei/L1 1684.htm>. Acesso em: 7 set. 2010.

BRASIL. Lei no 5.692, de 11 de agosto de 1971. Brasília, DF: Presidência da República: Casa Civil, 1971. Disponível em: <http://www.planalto.gov.br/ ccivil_03/leis/15692.htm>. Acesso em: 13 ago. 2011.

BRASIL. Lei no 9.394, de 20 de dezembro de 1996. Brasília, DF: Presidência da República: Casa Civil, 1996. Disponível em: <http://www.planalto.gov. br/ccivil_03/leis/L9394.htm>. Acesso em: 30 de nov. 2011.

CARROLL, Lewis. Alice no país das maravilhas. Petrópolis: Arara Azul, 2002.

CHAUÍ, Marilena. A situação da Filosofia. Correio do Povo, Porto Alegre, 11 nov. 1978. Caderno de Sábado, p. 8.

CORRÊA, Letícia Maria P. Ensino de Filosofia: um estudo de caso. Pelotas: Editora e Gráfica da Universidade Federal de Pelotas, 2012. 
CORTELLA, Mario Sérgio. Filosofia e ensino médio: certos porquês, alguns senôes, uma proposta. Petrópolis: Vozes, 2009.

COSTA, Cruz. Panorama da história da Filosofia no Brasil. São Paulo: Cultrix, 1960.

DELEUZE, Gilles; GUATTARI, Félix. O que é Filosofia?'Tradução de Bento Prado Jr. e Alberto Alonso Muñoz. Rio de Janeiro: Editora 34, 1992.

DEWEY, John. Reconstrução em Filosofia. São Paulo: Ícone, 2011.

DUTRA, Jorge C. O currículo de filosofia no ensino médio: em busca do diálogo entre os saberes abertos e os saberes específicos do campo filosófico. 2010. 120 f. Dissertação (Mestrado em Educação) - Faculdade de Educação. Programa de Pós-Graduação em Educação. Universidade Federal de Pelotas, Pelotas, 2012.

GOODSON, Ivor. Currículo: teoria e história. Petrópolis: Vozes, 1995.

HEGEL, G. W. F. Textes pédagogiques. Tradução de Bernard Bourgeois. Paris: Vrin, 1978.

KANT, Immanuel. Notícia do prof. Immanuel Kant sobre a organização de suas preleções no semestre de inverno de 1765-1766. In: KANT, Immanuel. Lógica. Trad. Guido Antônio de Almeida. Rio de Janeiro: Tempo Brasileiro, 1992.

LIPMAN, Matthew. O pensar na educação. Petrópolis: Vozes, 1995.

LOPES, Alice Casimiro; MACEDO, Elizabeth. Teorias de currículo. São Paulo: Cortez, 2011.

MALTA, Magno. Projeto de lei do Senado no 193, de 2016. Inclui entre as diretrizes e bases da educação nacional, de que trata a Lei no 9.394, de 20 de dezembro de 1996, o "Programa Escola sem Partido". Brasília, DF: Senado Federal, 2016. Disponível em: <https://www25.senado.leg.br/web/ atividade/materias/-/materia/125666>. Acesso em: 24 fev. 2018.

PAGNI, Pedro Angelo. Experiência estética, formação humana e arte de viver: desafios filosóficos à educação escolar. São Paulo: Loyola, 2014.

ROCHA, Ronai Pires da. Ensino de Filosofia e currículo. Petrópolis: Vozes, 2008. 
SAVIANI, Dermeval. Educação: do senso comum à consciência filosófica. Campinas: Autores Associados, 2009.

ZILLES, Urbano. Crer e compreender. Porto Alegre: EDIPUCRS, 2004.

Recebido em: 12 out. 2016.

Aceito em: 15 dez. 2016 